\title{
We are all fighters
}

\author{
Nanshan Zhong \\ National Clinical Research Center for Respiratory Disease, Guangzhou Institute of Respiratory Health, First Affiliated Hospital of Guangzhou \\ Medical University, State Key Laboratory of Respiratory Disease (Guangzhou Medical University), Guangzhou 510120, China \\ Correspondence to: Nanshan Zhong, MD. National Clinical Research Center for Respiratory Disease, Guangzhou Institute of Respiratory Health, First \\ Affiliated Hospital of Guangzhou Medical University, State Key Laboratory of Respiratory Disease (Guangzhou Medical University), Guangzhou \\ 510120, China. Email: nanshan@vip.163.com. \\ Provenance and Peer Review: This article was commissioned by the Editorial Office, Fournal of Thoracic Disease. The article did not undergo external peer review.
}

Submitted Feb 29, 2020. Accepted for publication Mar 10, 2020.

doi: $10.21037 /$ jtd.2020.03.01

View this article at: http://dx.doi.org/10.21037/jtd.2020.03.01

The COVID-19 epidemic, which is attributed to a novel coronavirus of zoonotic origin (SARS-CoV-2), has endured for 3 months (1). Globally, over 80,000 people have been infected, with more than 3,000 resulting deaths. China has borne most of the disease burden, especially Hubei province, the epicenter of the outbreak. On January 23, 2020, China implemented strict measures in an effort to control the epidemic; these included a quarantine of the Greater Wuhan area, the extension of national holidays, and rigorous monitoring of civilian activities. These interventions have effectively restricted population migration and movement and have caused significant social, economic, and psychological disruption across the country. It is imperative to know if these measures have proved effective and for how long they should remain in place. Owing to the unprecedented nature of this outbreak and the control measures implemented, modelling studies are useful to simulate and predict epidemic trends under a desired scenario.

The epidemic occurred just before the 2020 Spring Festival in Wuhan, one of China's busiest transportation hubs. As a result, the population's migratory activity is fundamental in trying to understand the spread and progression of this epidemic. One of the earliest studies to incorporate migration data to predict the spread of the epidemic was produced by a team from The University of Hong Kong (2). Using exported COVID-19 cases and migration data from Wuhan, they inferred the epidemic breakout size and predicted the outward spread of the disease to other major cities. Importantly, their model predicted that Wuhan-sized outbreaks would occur in other major Chinese cities if control measures were not put in place. However, their study used data only up to January 21 , and was in no way able to account for the impact of the control measures implemented on January 23.

The impact of the control measures is reflected in the current epidemic situation. Although Hubei, and in particular Wuhan, is still suffering disproportionately, outbreaks in other cities have largely been brought under control, with cases outside of Hubei accounting for only $20 \%$ of the total number reported nationally. In this issue of Fournal of Thoracic Disease (fTD) (3), Yang et al., attempted to provide a prediction of the epidemic trends based on the current situation in China (i.e., after the implementation of control measures). They used a dynamic Susceptible-Exposed-Infectious-Recovered model incorporating the population migration data before and after January 23 to reflect the impact of the national intervention. Based on our more recent understanding of the virus's transmissibility, they included a key assumption: that the disease is transmissible during the incubation period, which is a key difference between SARS-CoV-2 and SARS-CoV. Their model also accounts for the reduced contact rate resulting from quarantining and socialdistancing measures.

As China is currently experiencing a downward trend in new COVID-19 infections, we are able to see that their prediction so far has fairly accurate. The epidemic peak time and size predicted by their model have closely reflected the current actual reported data, particularly for Guangdong and Zhejiang. The situation in Hubei has been complicated by the change in the reporting process. Even so, Yang et al.'s prediction still remains within 
reasonable range of the actual situation. Importantly, their model predicted that we are on a downward trend and, with the exception of Hubei, the epidemic should settle down by the end of April. This observation was supported by their use of an artificial-intelligence (AI) machine learning-based prediction.

In any modelling study, accurate epidemiological data and assumptions are critical. Early understanding of an epidemic progression is important for timely intervention, but model predictions are less robust due to the lack of solid epidemiological data. Perhaps the use of AI technology, which can take past experiences into account, can be harnessed to overcome this pitfall and improve our response to outbreaks in the future.

\section{Acknowledgments}

Funding: None.

\section{Footnote}

Conflicts of Interest: NZ serves as the unpaid Editor-in-Chief of Fournal of Thoracic Disease.

Ethical Statement: The author are accountable for all aspects of the work in ensuring that questions related to the accuracy or integrity of any part of the work are appropriately investigated and resolved.

Open Access Statement: This is an Open Access article distributed in accordance with the Creative Commons Attribution-NonCommercial-NoDerivs 4.0 International License (CC BY-NC-ND 4.0), which permits the noncommercial replication and distribution of the article with the strict proviso that no changes or edits are made and the original work is properly cited (including links to both the formal publication through the relevant DOI and the license). See: https://creativecommons.org/licenses/by-nc$\mathrm{nd} / 4.0 /$.

\section{References}

1. Guan WJ, Ni ZY, Hu Y, et al. Clinical Characteristics of Coronavirus Disease 2019 in China. N Engl J Med 2020. [Epub ahead of print].

2. Wu JT, Leung K, Leung GM. Nowcasting and forecasting the potential domestic and international spread of the 2019-nCoV outbreak originating in Wuhan, China: a modelling study. Lancet 2020;395:689-97.

3. Yang Z, Zeng Z, Wang K, et al. Modified SEIR and AI prediction of the epidemics trend of COVID-19 in China under public health interventions. J Thorac Dis 2020;12:165-74.
Cite this article as: Zhong N. We are all fighters. J Thorac Dis 2020;12(3):132-133. doi: 10.21037/jtd.2020.03.01 